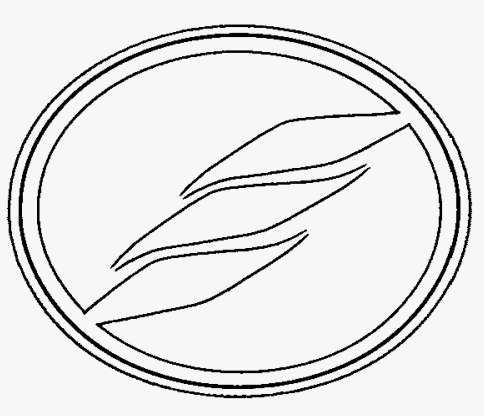

INEEL/EXT-98-01083

R!

$$
\begin{aligned}
& \text { MAY, Octób. 19998 } \\
& \text { OST/ }
\end{aligned}
$$

Failure Criteria for Evaluating Accidental Drops of Fuel Containers at INTEC

G. K. Miller

LOCKHEED MARTIN 


\section{DISCLAIMER}

Portions of this document may be illegible in electronic image products. Images are produced from the best available original document. 
INEEL/EXT-98-01083

\title{
Failure Criteria for Evaluating Accidental Drops of Fuel Containers at INTEC
}

\author{
G. K. Miller
}

Published October 1998

Idaho National Engineering and Environmental Laboratory Specialty Engineering and Science Department Lockheed Martin Idaho Technologies Company Idaho Falls, Idaho 83415 


\section{Failure Criteria for Evaluating Accidental Drops of Fuel Containers at INTEC}

Author: G.K.Miller $\quad y_{K}$ Willen $10-22-98$ Specialty Engineering \& Science

Checked: S. R. Jensen



Specialty Engineering \& Science

Approved: A. G. Ware

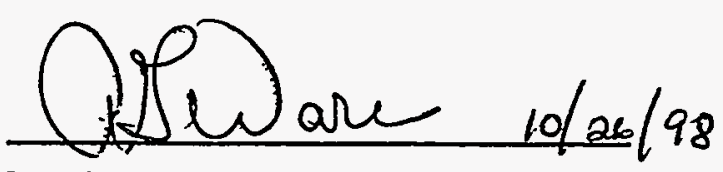
Supervisor, Specialty Engineering \& Science.

Approved: C. A. Moore

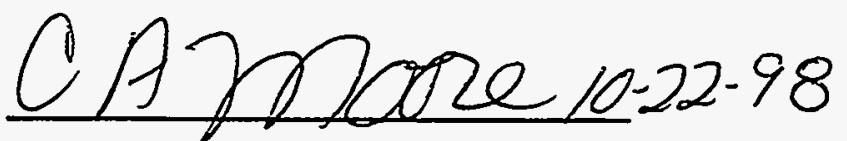
Supervisor, INTEC Design Engineering 


\section{CONTENTS}

ABSTRACT

SUMMARY

INTRODUCTION

PURPOSE

ASSUMPTIONS

FAILURE CRITERION

OTHER CONSIDERATIONS

Strain Rate $\quad 5$

$\begin{array}{ll}\text { Hydrostatic Stresses } & 10\end{array}$

GUIDELINES AND RECOMMENDATIONS 11

Failure Criterion Based on Ultimate Strain $\quad 11$

304 Stainless Steel (ASTM) . . 11

304L Stainless Steel (ASTM) 14

6061 T6 Aluminum (ASTM) 14

Annealed 6061 Aluminum 14

Lead 14

Failure Criterion Based on Energy Density 14

CONCLUSION 14

$\begin{array}{ll}\text { REFERENCES } & 15\end{array}$

\section{FIGURES}

1. Typical stress-strain curves for structural steels 4

2. Effect of strain rate on the tensile properties of Type 304 stainless steel 7

3. Compressive stress-strain curves 6061-T6 aluminum at differing strain rates 8

4. Compressive true-stress and true-strain curves for annealed 6061 aluminum 9

5. Stress-strain curves of lead and tin at room temperature 9

6. The strain at fracture versus pressure for various steels 11 
7. Failure criteria for Type 304 stainless steel

8. True stress-true strain tensile data for Type 304 stainless steel 


\section{ABSTRACT}

This report presents a failure criterion that has been developed for use in evaluating fuel containers at the Idaho Nuclear Technology and Engineering Center (INTEC) for accidental drop events. The criterion would typically be used in dynamic finite element analyses using the ABAQUS/Explicit program. The failure criterion used in the past is generally considered to substantially underestimate the strength and ductility of the materials involved. The new criterion is intended to be more realistic, allowing for more accurate impact analyses. The criterion is based on the distortion energy theory, which is considered to be appropriate for the ductile materials typically used in fuel containers.

Also addressed in development of the criterion were the effects of strain rate and hydrostatic stress. The importance of these factors, however, is highly dependent on the material used. Three materials specifically addressed in this study were stainless steel, aluminum, and lead. The criterion is presented in the form of guidelines and recommendations that are based on material data obtained from the literature. The most significant difference between these and the previous criterion is that ductile materials are allowed to strain to much higher levels before they are considered to fail. 


\section{SUMMARY}

This report presents a failure criterion that have been developed for use in evaluating fuel containers at the Idaho Nuclear Technology and Engineering Center (INTEC) for accidental drop events. The criterion would typically be used in dynamic finite element analyses using the ABAQUS/Explicit program. The failure criterion used in the past does not account for a large portion of the strength and ductility of material that is available in most situations. The new criterion is intended to be more realistic, allowing for more accurate impact analyses.

The general approach to modeling a failure criterion in the ABAQUS/Explicit program is to specify an equivalent plastic strain at which the material will fracture. The criterion currently used in evaluating container drops specify a strain limit based on ultimate elongation for the material. A concern is that this neglects much of the available strength and ductility of material for many applications.

Establishing a failure criterion relies on selecting a failure theory as a basis. The theory selected herein is the distortion energy theory, which is considered to be representative for the ductile materials typically used in fuel containers. This theory can be applied in an approximate manner by specifying a limit on equivalent plastic strain for a material. This is consistent with the general approach provided in the ABAQUS/Explicit program. Alternatively, the theory could be applied more precisely by specifying a limit on distortion energy density. This may be feasible using a subroutine in ABAQUS/Explicit, but has not been demonstrated herein.

The new failure criterion recommended herein differs significantly from the current criterion in basing material failure on ultimate true strain rather than ultimate elongation. For ductile materials, this makes a substantial difference in energy absorbed before the material fails. This difference means that the new criterion takes much greater credit for available ductility of the material than does the current criterion.

Also addressed in development of this criterion were the effects of strain rate and hydrostatic stress. The importance of these factors, however, is highly dependent on the material used. Three materials specifically addressed in this study were stainless steel, aluminum, and lead. The strain rates and hydrostatic stresses experienced in accidental drops should have only a moderate effect on failure of the stainless steel and aluminum used in fuel containers, but a more significant effect on failure of lead. This is because lead is generally a thicker confined material when used in these containers.

The new criterion is presented in the form of guidelines and recommendations that are based on material data obtained from the literature. This criterion is applied in the same manner as the current criterion. The material property data have been adjusted to more realistically represent material behavior. The criterion should be generally applicable for modeling ductile materials in impact events, but may not represent the best approach in all situations. The analyst must consider any phenomena that may impair ductile behavior of the material in a particular situation, and model the behavior accordingly. 


\section{INTRODUCTION}

Numerous dynamic finite element analyses have been performed to evaluate fuel containers at the Idaho Nuclear Technology and Engineering Center (INTEC) for accidental drop events. In most of these drop events, at least some of the material in the container undergoes plastic deformation. In many cases the deformation reaches a point where material actually fails. While failure of material is not necessarily catastrophic, it generally affects the behavior of the container through the remainder of the drop event. Therefore, the more realistically the failure of material is modeled, the more accurate is the analysis of the container in the drop event. The difficulty comes in establishing a realistic failure criterion for the materials involved in these drop events, which will include a suitable safety factor where necessary.

A general approach to modeling failure of material in the ABAQUS/Explicit computer program is to specify a maximum equivalent plastic strain at which the material will fracture. Once this strain level is reached within a finite element during the analysis, that element is eliminated from the model. The user must define an "offset" plastic strain (a strain level in the solution where the material begins to fail), and a failure strain (which is the highest strain attainable in the material during the solution). The stress decreases linearly between these two strain values to a value of zero at the failure strain, which allows for stable failure of material in the ABAQUS solution.

A failure criterion that has typically been used in evaluating accidental drops of fuel containers at INTEC is outlined in Ref. 1. The criterion is based on material properties obtained from uniaxial tension tests and reads as follows:

The calculated equivalent strain is limited to $2 / 3$ of the minimum specified (ASTM) ultimate elongation for the material.

This is a general criterion that can be used to evaluate a variety of containers fabricated from ductile material. It has commonly been applied in ABAQUS solutions by setting the failure strain equal to the minimum specified ultimate elongation for the material and setting the "offset" strain equal to $2 / 3$ of this value. A concern is that the use of this criterion may, in many applications, neglect much of the available ductility in the material. The purpose of the investigation performed herein is to establish a criterion that is more realistic. It is intended that the criterion be simple enough to apply that it can be used by an analyst who is not necessarily an expert in material failure theories.

\section{PURPOSE}

The purpose for establishing a new failure criterion is to allow for more realistic simulations of accidental drops of fuel containers. A criterion that does not recognize the full strength or ductility of the material results in analyses that predict a greater level of damage to material in the vicinity of the impact than would actually occur. Use of such a criterion will, however, predict a softer than realistic landing, thereby delivering a lower than realistic impact force to the re- 
mainder of the container (such as the contents). This means that the analysis could predict a lesser level of damage to other portions of the container than would actually occur, depending on how they are analyzed.

The criterion presented herein is intended to allow for realistic simulations by basing the criterion on more accurate estimates of the strength and ductility of the material than have been used in the past. A concern is that use of the previous criterion results in predicting too much damage to material in many drop events. The intent of the new criterion is to still underestimate the strength and ductility of the material, but to a much lesser degree. With this criterion, failure of material should be predicted to occur earlier than would actually happen during an event.

\section{ASSUMPTIONS}

The criterion presented is based on the assumption of ductile failure in a material. It is intended specifically to be used in the analysis of accidental drops of a container, and is not necessarily applicable to other failure scenarios. It may not apply, for example, when notches or defects are present or when a state of significant triaxial tensile stress exists.

Additionally, the criterion may not be accurate once a tension crack develops and grows to such size that the failure mode transitions from ductile to brittle fracture.

Failure criteria are given herein specifically for 304 (and 304L) stainless steel, $6061 \mathrm{~T} 6$ and annealed aluminum, and common lead. The approach presented herein can be used for other ductile materials as well. For materials such as carbon steel, though, the weld metal may not be as ductile as the base material, in which case the failure criterion in the welded portions of the container would have to be adjusted to reflect this loss of ductility.

\section{FAILURE CRITERION}

Establishing a failure criterion relies on selecting a failure theory as a basis. The failure theory selected herein must be appropriate for the ductile materials typically used in the fuel containers used at INTEC. The theory must account for differing multiaxial stress states, though the preponderance of available material property data have been obtained from uniaxial tension tests. Since it is not feasible to test all materials for all possible states of stress, failure theories are typically gauged to data obtained from uniaxial stress tests. Ref. 2 presents six such failure theories, and notes that the 'distortion energy theory' has proven to be the best among these for predicting failure in ductile materials in multiaxial stress states. This theory is therefore adopted here as a basis for establishing a failure criterion.

The distortion energy theory is stated as follows:

Failure is expected to occur in the multiaxial state of stress when the distortion energy per unit volume reaches or exceeds the distortion energy per unit volume at the time of failure in a simple uniaxial stress test using a specimen of the same material. 
Ref. 2 then develops this theory on an elastic basis with the result that failure is predicted to occur when the effective (von Mises) stress exceeds the uniaxial failure strength. Ref. 2 states that, though this criterion was determined on an elastic basis, data indicate that the theory is valid well into the plastic range. The reference presents results from biaxial tests showing this to be the case for several ductile materials.

The distortion energy theory could be developed on an elastic basis in terms of strain rather than stress. It is readily shown that the result is that failure would be predicted to occur when the equivalent strain exceeds the uniaxial failure strain. (This assumes an incompressible material typical for plastic behavior of ductile materials.) It is instructive, however, to consider the distortion energy theory on the basis of plastic behavior.

In Ref. 3, the Prandtl-Reuss plastic flow equations are used in showing that the distortion energy per unit volume in plasticity is (assuming isotropic hardening):

$$
W=\int \sigma_{e} d \epsilon_{p}
$$

where $\sigma_{\mathrm{e}}$ is the effective (von Mises) stress and $\varepsilon_{\mathrm{p}}$ is the effective (or equivalent) plastic strain. To apply the distortion energy theory, we must also determine what this gives in the case of the uniaxial stress state. If the stress occurs in the 1-direction during the uniaxial test, then

$$
\sigma_{e} \rightarrow \sigma_{1} \quad d \epsilon_{p} \rightarrow d \epsilon_{1}
$$

Based on the distortion energy theory, then, failure in a multiaxial stress state is expected to occur when

$$
\int \sigma_{e} d \epsilon_{p} \geq \int_{f} \sigma_{1} d \epsilon_{1}
$$

The $f$ on the right-hand side (RHS) denotes that the integral is taken to failure in the uniaxial stress test. To obtain exact values for these integrals, one has to integrate over the entire history of loading. This can be done in a finite element dynamic analysis to obtain the left-hand side of the equation. The RHS can be obtained by integrating the true stress-strain curve obtained from uniaxial test data. Using this energy density relationship is the truest way of applying the distortion energy theory. It may be possible to do this using the ABAQUS/Explicit program, details of which are described later.

As an alternative, a reasonable approximation can be attained by assuming that the individual stress components increase (or decrease) at the same rate as the loading is applied. The criterion above then becomes

$$
\epsilon_{p} \geq \epsilon_{1 f}
$$


The $2 / 3$ factor imposed in the failure criterion of Ref. 1 was applied to provide a safety margin against failure. The criterion of Ref. 1, though, significantly underestimates the material ductility in limiting the calculated equivalent strain on the basis of elongation rather than ultimate true strain. Once the material in a ductile test specimen necks down, the true strain in the necked-down portion can significantly exceed the elongation for the specimen. For example, Fig. 1 presents a stress-strain curve for A36 carbon steel obtained from Ref. 4. The 'strain' values in this figure are actually a measure of the material elongation. As shown in the figure, the elongation reached a value of 0.23 in/in at failure. Ref. 4 also indicates that the reduction in area at failure for this material is about $50 \%$. This translates to a true strain of

$$
\epsilon_{t r}=\ln \frac{A_{i}}{A_{f}}=\ln (2)=0.69 \mathrm{in} / \text { in } \quad \begin{aligned}
& A_{i}=\text { initial area } \\
& A_{f}=\text { final area }
\end{aligned}
$$

As this demonstrates, the elongation is typically considerably less than the ultimate true strain for ductile materials. Thus, the current failure criterion neglects considerable ductility of the material. The failure criterion recommended herein will be based on true strain rather than elongation.

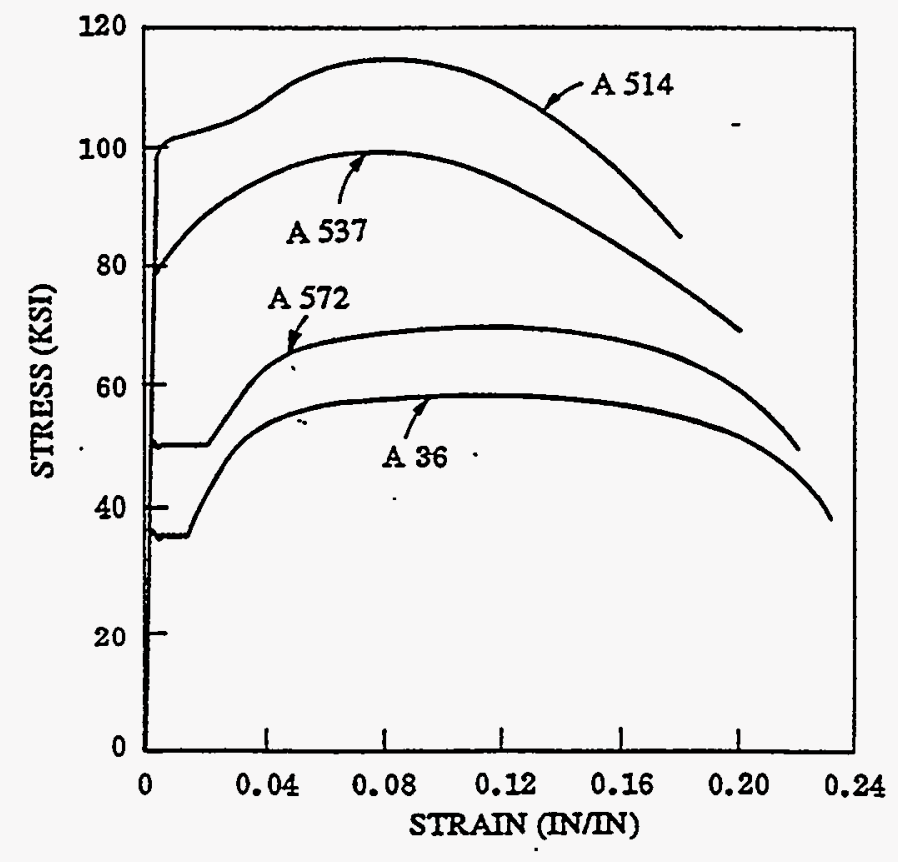

Figure 1. Typical stress-strain curves for structural steels. 


\section{OTHER CONSIDERATIONS}

Before directly applying the failure criterion determined above, other factors must be considered which could affect the stress-strain behavior of the materials under impact conditions. The most significant of these are the strain rate and the presence of hydrostatic stresses. The importance of these factors, however, is highly dependent on the materials in question. Three materials addressed herein that are commonly used in fuel containers at INTEC are stainless steel, aluminum, and lead.

\section{Strain Rate}

Relative to Type 304 stainless steel, Fig. 2 (obtained from Ref. 5) shows the effect of strain rate on the ultimate stress, yield stress, reduction-in-area (RA), and total elongation. The maximum strain rates in a drop event will often exceed the maximum rate of $100 \mathrm{in} / \mathrm{in} / \mathrm{sec}$ shown in these curves. The figure is, however, useful in showing trends for these material properties. While the initial $(0.2 \%$ offset) yield stress increases significantly with strain rate, the ultimate stress is relatively unaffected. The ductility, as measured by RA and elongation, decreases with strain rate. The increase in yield stress and the decrease in RA have offsetting effects relative to the total area beneath the stress-strain curve. Based on these data, the initial yield stress for 304 stainless steel could be increased to $50 \mathrm{ksi}$ for impact analyses, while the ultimate stress is left at its minimum specified value of $75 \mathrm{ksi}$ (which must be converted to a true stress). The ultimate true strain will be based on the minimum RA of Fig. 2 (i.e. 60\%) as follows:

$$
\epsilon_{t r}=\ln \left(\frac{1}{.4}\right) \approx 0.9 \mathrm{in} / \mathrm{in}
$$

Type 304L stainless steel is a form of 304, having a lower carbon content. It has a slightly lower strength than 304 but can be expected to have essentially the same ductility. Based on the lower strength, the initial yield stress should be set to $40 \mathrm{ksi}$, while the ultimate stress is set at its minimum specified value of $70 \mathrm{ksi}$. The ultimate true strain should be set equal to that of 304 stainless, i.e. $0.9 \mathrm{in} / \mathrm{in}$.

For 6061 T6 aluminum, Fig. 3 (obtained from Ref. 5) shows the effect of strain rate on the compression stress-strain behavior for rates up to $2700 \mathrm{in} / \mathrm{in} / \mathrm{sec}$. At normal temperatures, the strain rate does not have a significant effect on the behavior shown. Therefore, static stress values should be adequately representative of $6061 \mathrm{~T} 6$ aluminum under impact conditions. Fig. 3 does not show the ultimate strain for $6061 \mathrm{~T} 6$ aluminum. Uniaxial tests described in Ref. 6, however, indicated the ultimate true strain to be $0.39 \mathrm{in} /$ in under static conditions. Expecting that there is some loss in ductility under impact conditions, it is suggested that this be reduced to 0.30 in/in when modeling for impact. For annealed 6061 aluminum, Fig. 4 (obtained from Ref. 5) shows 
the effect of strain rate on compression stress-strain behavior for rates up to $1500 \mathrm{in} / \mathrm{in} / \mathrm{sec}$. Dynamic conditions increase the true stress by about $20 \%$. Therefore, static true stresses could be amplified by a factor of up to 1.2 for annealed 6061 aluminum under impact conditions. Since the ultimate strain for annealed 6061 should be at least that of $6061 \mathrm{~T} 6$, it is recommended that a value of $0.30 \mathrm{in} / \mathrm{in}$ also be used.

Ref. 7 indicates that the material properties of lead are significantly affected by strain rate. However, test results have shown considerable variability in the dynamic properties of lead, making it difficult to establish definitive properties for impact conditions. Ref. 7 speaks in terms of a "dynamic flow stress", which is the energy required to displace $1 \mathrm{in}^{3}$ of material. This is also the area under the stress-strain curve for the material. It is suggested in Ref. 7 that $5000 \mathrm{lb}-\mathrm{in} / \mathrm{in}^{3}$ is a reasonable value to use for dynamic flow stress when estimating lead deformation, and that $10,000 \mathrm{lb}-\mathrm{in} / \mathrm{in}^{3}$ is reasonable when estimating maximum deceleration loading. Modeling lead to have these dynamic flow pressures can be accomplished in a number of ways. It is recommended herein that the ultimate strain be based on the stress-strain curve for lead shown in Fig. 5 (obtained from Ref. 8). This shows the ultimate strain under static conditions to be on the order of $0.8 \mathrm{in} / \mathrm{in}$. This will not be decreased for strain rate effects because of compensating effects of hydrostatic stress (discussed below). It is reasonable to straddle the 0.8 strain value by setting the offset strain to $0.6 \mathrm{in} / \mathrm{in}$ and the failure strain to $0.9 \mathrm{in} / \mathrm{in}$ using the ABAQUS/Explicit failure criterion. A second assumption is that the lead has a constant engineering yield stress. The yield stress at a strain of $0.6 \mathrm{in} / \mathrm{in}$ will be converted to its true stress. For a dynamic flow stress of 5000 $\mathrm{lb}-\mathrm{in} / \mathrm{in}^{3}$, then, the initial yield stress will be set at $4500 \mathrm{psi}$ and the true stress at the offset strain of $0.6 \mathrm{in} /$ in will be set at $8100 \mathrm{psi}$. Stresses should be linearized between these values. With the failure strain set at $0.9 \mathrm{in} / \mathrm{in}$, the total area under the stress-strain curve equals $5000 \mathrm{lb} / \mathrm{in}^{2}$, as it should. For a flow stress of $10000 \mathrm{lb}$-in/in ${ }^{3}$, the initial yield stress and the stress at the offset strain of $0.6 \mathrm{in} /$ in should simply be doubled to $9000 \mathrm{psi}$ and $16,200 \mathrm{psi}$, respectively. The initial yield stress should, in both cases, be preceded by a region of elasticity. 

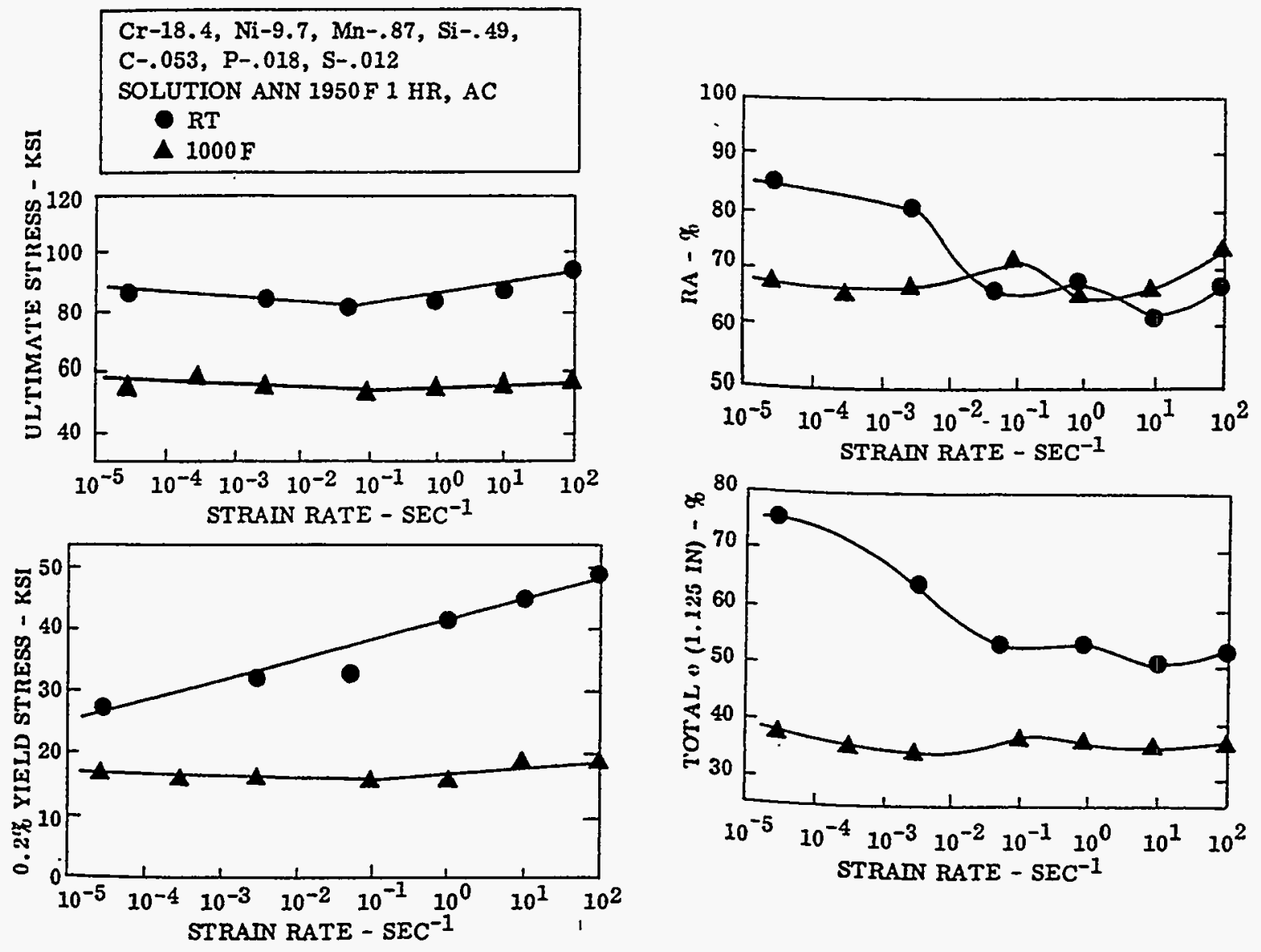

Figure 2. Effect of strain rate on the tensile properties of Type 304 stainless steel. 

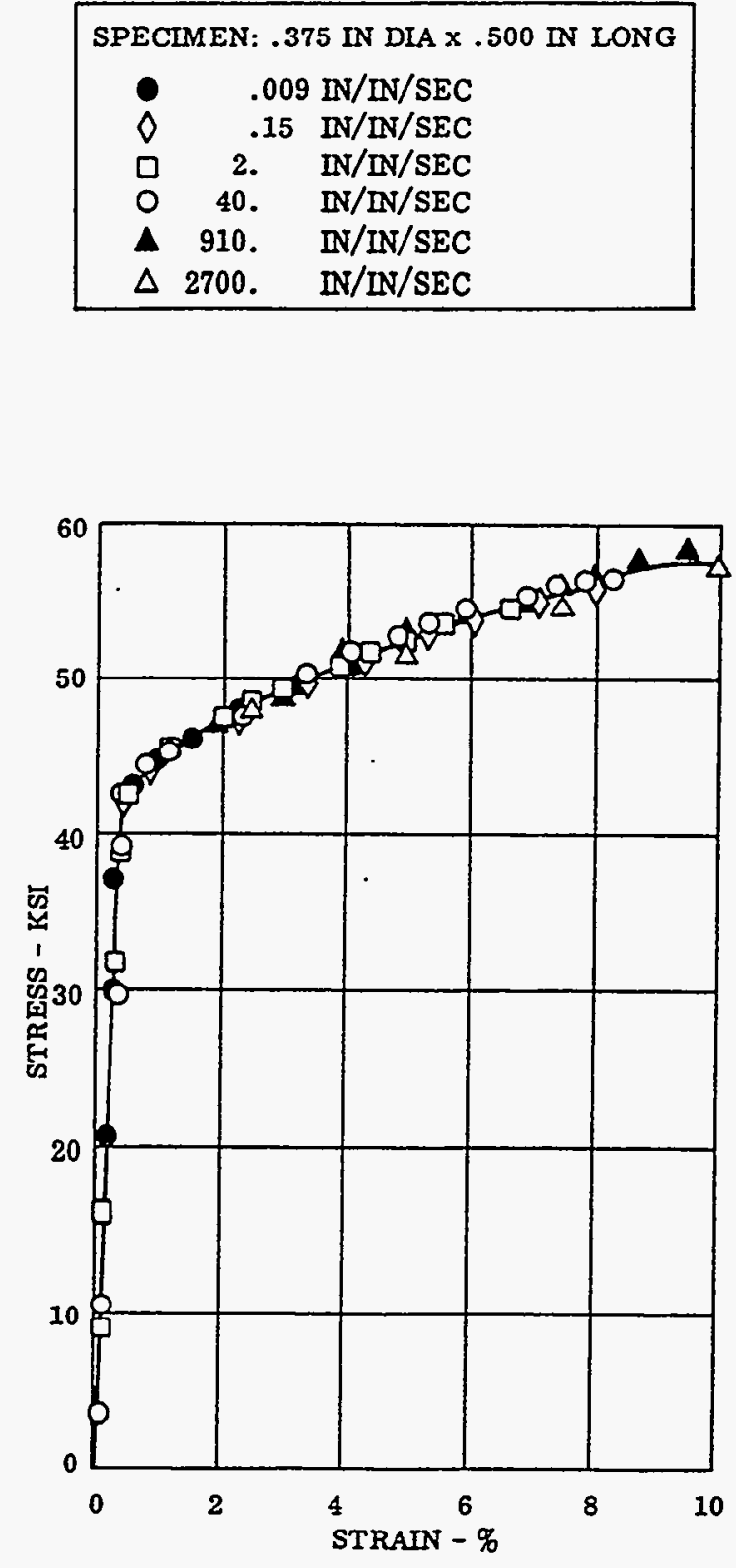

Figure 3. Compressive stress-strain curves for 6061-T6 aluminum at differing strain rates. 

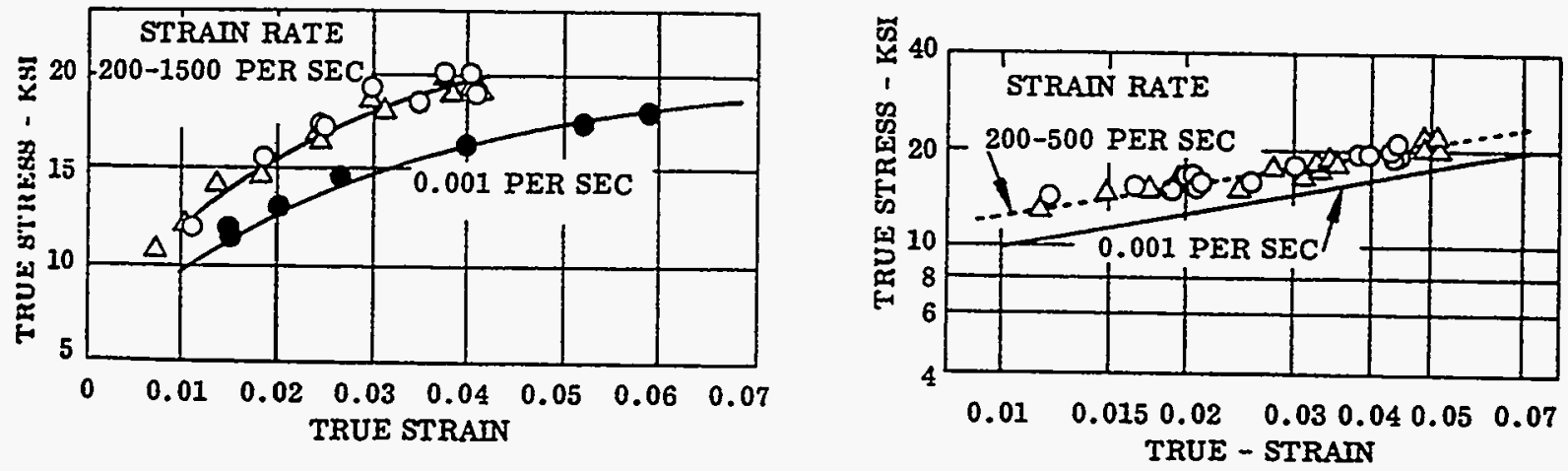

Figure 4. Compressive true-stress true-strain curves for annealed 6061 aluminum.

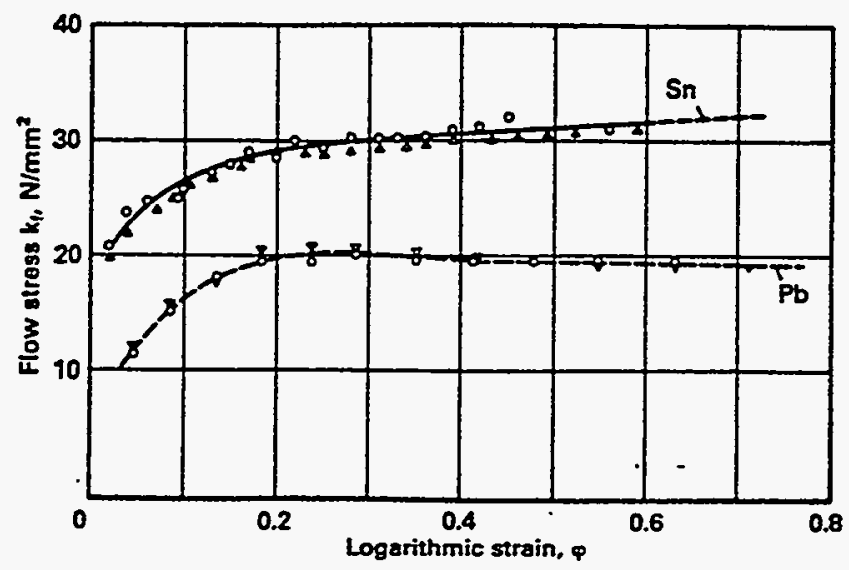

Figure 5. Stress-strain curves of lead and tin at room temperature. 


\section{Hydrostatic Stresses}

The ductility of a material can be affected significantly by the presence of hydrostatic stress. A ductile material will typically fail with an increased ductility if the hydrostatic stress is compressive, or fail with decreased ductility if the hydrostatic stress is tensile (Ref. 9). Per the von Mises yield criterion, hydrostatic stress does not contribute to the initial yielding of material. It does, however, affect fracture of the material. Ref. 10 explores the effects of hydrostatic stress by subjecting test specimens to large pressure loading (ranging up to several hundred thousand psi) in addition to normal test loading. The pressure represents a compressive hydrostatic stress. Most of the tests were performed on steels, with results showing that the pressure loads typically had a dramatic effect on the true strain at which the material fractured. Test results for four different steels are presented in Fig. 6 . Steel 18 is a stainless steel having a material composition very nearly that of 304 stainless steel. It is evident that its ductility is not as sensitive to hydrostatic stress as it is for the other steels. The 304 stainless steel used in fuel containers at INTEC is typically in the form of shells or end plates, i.e., components that are generally too thin to develop significant hydrostatic stresses. For these reasons, the effect of hydrostatic stress can typically be ignored when modeling 304 stainless steel in accidental drop events. It would normally be conservative to do so, unless the material were in a state of significant triaxial tension.

It is very difficult to find data showing the effects of hydrostatic stress on any particular alloy of aluminum. Ref. 10 indicates that the effects in general are probably similar to those on steel. The use of aluminum in fuel containers at INTEC is again typically in components that are too thin to develop significant hydrostatic stresses. It is therefore recommended that the effect of hydrostatic stress be ignored when modeling aluminum alloys in accidental drop events.

It is also difficult to find data that specifically shows the effects of hydrostatic stress on the ductility of lead. The lead shielding used in fuel containers or casks at INTEC is generally thick confined material, meaning that the effects of hydrostatic stress are likely to be significant. Since the lead should generally experience compressive hydrostatic stress during an impact event, its ductility can normally be expected to increase. The effects of both strain rate and hydrostatic stress on the behavior of lead are accounted for by following the modeling recommendations given above. This is because the values used for dynamic flow stress for the material (as obtained from Ref. 7) are based on test results that should include both effects. The modeling recommendations are reiterated in the section below. 


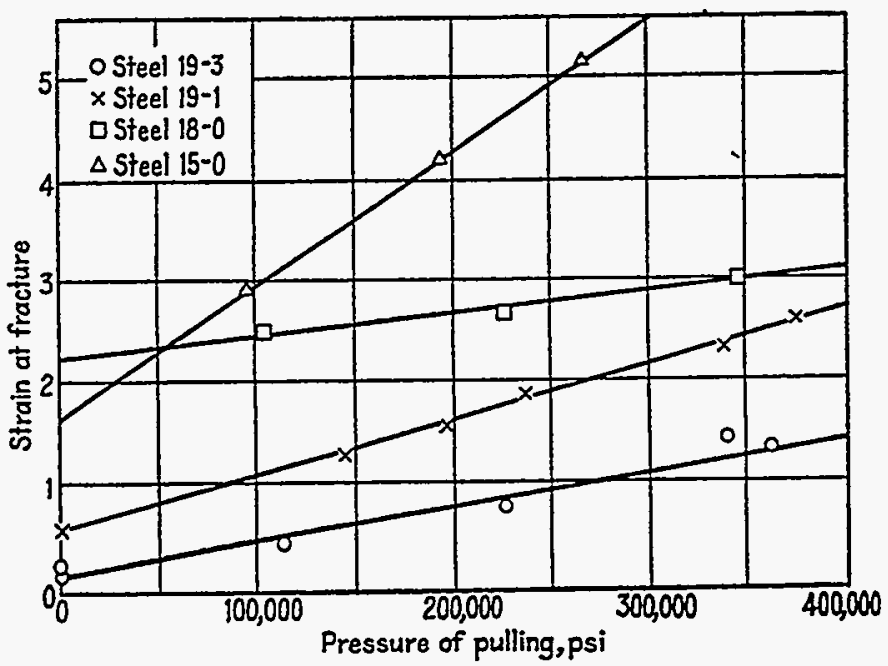

Figure 6. The strain at fracture versus pressure for various steels.

\section{GUIDELINES AND RECOMMENDATIONS}

\section{Failure Criterion Based on Ultimate Strain}

The above considerations indicate that the failure criterion currently used for ductile materials in evaluating accidental drops of fuel containers at INTEC significantly underestimates the material ductility. The primary reason for this is that the criterion is based on ultimate elongation for the material rather than true ultimate strain. Other factors potentially having an effect are strain rate and hydrostatic stress. Guidelines for treating failure of three specific materials used in fuel containers at INTEC are summarized below:

\section{Stainless Steel (ASTM)}

For Type 304 stainless steel, the failure criterion of ABAQUS/Explicit (*FAIIURE) can be used. It is recommended that the equivalent plastic strain at failure be set to $0.9 \mathrm{in} / \mathrm{in}$. To provide a safety margin in predicting fracture of material, the offset plastic strain at the start of failure should be set to about $2 / 3$ of $0.9 \mathrm{in} / \mathrm{in}(-0.6 \mathrm{in} / \mathrm{in})$. If a safety margin is not needed, then the offset 
strain could be set to a higher value than $0.6 \mathrm{in} / \mathrm{in}$. (It is noted that instability in the ABAQUS solution may occur if the offset strain is set too close to the failure strain.) The initial yield stress for 304 stainless steel could be increased to $50 \mathrm{ksi}$ for impact analyses, while the ultimate stress should be left at its minimum specified value of $75 \mathrm{ksi}$. The ultimate engineering stress is reached in a uniaxial tension test when the test specimen begins to neck down. Therefore, this ultimate stress can be converted to a true stress using a strain value representative of the initiation of necking.

A stress-strain curve for 304 stainless steel that meets these criteria is shown in Fig. 7. In the curve, the yield stress for the material is set at $50 \mathrm{ksi}$. The modulus of elasticity is set at $28 \times 10^{6}$ psi, which gives a strain at yield of $0.00178 \mathrm{in} / \mathrm{in}$ (point 1 on the curve). The engineering ultimate stress is set at the ASTM specified minimum value of $75 \mathrm{ksi}$. Data in Ref. 8 indicates that the material necks down at an engineering strain of about $0.7 \mathrm{in} / \mathrm{in}$ (which converts to a true strain of $0.53 \mathrm{in} / \mathrm{in}$ ). At this strain level, the ultimate stress of $75 \mathrm{ksi}$ converts to a true stress of 127.5 ksi (point 2). The true stress-true strain curve shown in Fig. 8 (Ref. 5) shows that true stress can actually be expected to reach values well above $127.5 \mathrm{ksi}$ at room temperature. To provide a safety margin in the failure criterion, though, the offset plastic strain is set equal to the true strain at point $2(0.53 \mathrm{in} / \mathrm{in})$. The true stress ramps downward from point 2 to a value of zero at a true strain of 0.9 (point 3 ).

In Fig. 7, the stress-strain curve is ramped downward from point 2 to point 3 to provide a safety margin in determining when failure occurs in the material. The actual stress-strain curve continues on a path indicated by the dashed line to a point 4 . (This dashed line is not intended to give precise values). The region 2-3-4 in the figure, therefore, represents energy absorption capacity (ductility) that is available in the material but neglected in this failure criterion. 


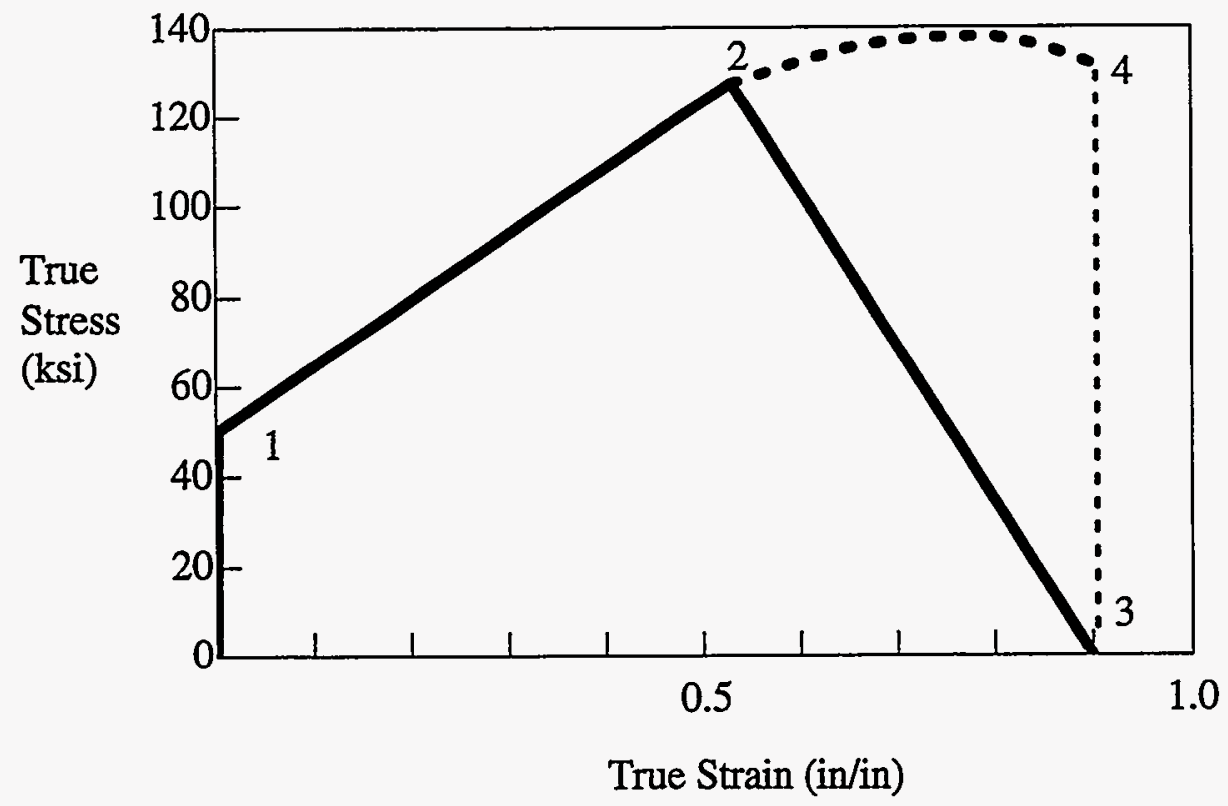

Figure 7. Failure criteria for Type 304 stainless steel.

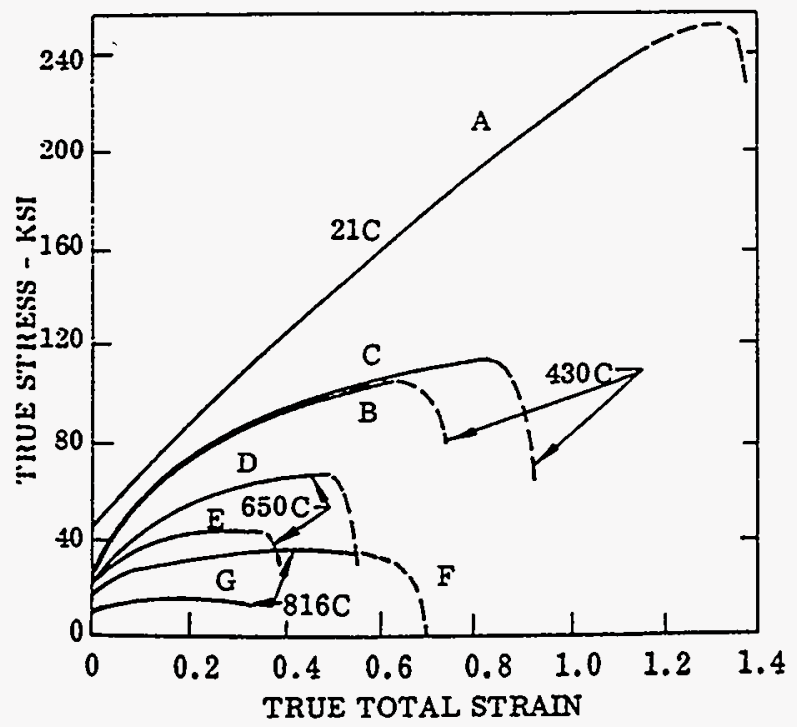

Figure 8. True stress-true strain tensile data for Type 304 stainless steel. 


\section{L Stainless Steel (ASTM)}

The same properties as used for 304 stainless steel can also be used for 304L stainless steel, except that the yield strength and ultimate strength are reduced to $40 \mathrm{ksi}$ and $70 \mathrm{ksi}$, respectively.

\section{T6 Aluminum (ASTM)}

For $6061 \mathrm{~T} 6$ aluminum, the failure criterion of ABAQUS/Explicit can be used. It is recommended that the equivalent plastic strain at failure be set to $0.3 \mathrm{in} / \mathrm{in}$. To provide a safety margin in predicting initial fracture, the offset plastic strain at the start of failure should be set to about $2 / 3$ of $0.3 \mathrm{in} / \mathrm{in}(-0.2 \mathrm{in} / \mathrm{in})$. If a safety margin is not needed, then the offset strain could be set to a higher value. It is recommended that static values be used for yield and ultimate stress. No further adjustments should normally be required to account for the effects of strain rate or hydrostatic stress.

\section{Annealed 6061 Aluminum}

For annealed 6061 aluminum, it is similarly recommended that the equivalent plastic strain at failure be set to $0.3 \mathrm{in} / \mathrm{in}$, with an offset strain of $0.2 \mathrm{in} / \mathrm{in}$, unless higher values can be justified. It is recommended that values for stress on its static stress-strain curve be amplified by 1.2 for impact conditions.

\section{Lead}

It is recommended herein that lead be modeled to give a dynamic flow pressure of $5000 \mathrm{lb}$-in/in ${ }^{3}$ when deformations are of concern or $10,000 \mathrm{lb}-\mathrm{in} / \mathrm{in}^{3}$ when deceleration loading is of concern. This can be accomplished by setting the offset strain to $0.6 \mathrm{in} / \mathrm{in}$ and the failure strain to $0.9 \mathrm{in} /$ in using the ABAQUS/Explicit failure criterion. For the case of a $5000 \mathrm{lb}-\mathrm{in} / \mathrm{in}^{3}$ flow pressure, the initial yield stress can be set at $4500 \mathrm{psi}$ and the true stress corresponding to the offset strain of $0.6 \mathrm{in} / \mathrm{in}$ can be set at $8100 \mathrm{psi}$. Stresses should be linearized between these values. For the case of a 10,000 lb-in/in ${ }^{3}$ flow pressure, the initial yield stress and the true stress at the offset strain of 0.6 should be doubled to $9000 \mathrm{psi}$ and $16,200 \mathrm{psi}$, respectively. The initial yield stress should, in both cases, be preceded by a region of elasticity.

\section{Failure Criterion Based on Energy Density}

As stated earlier, a truer way of applying the distortion energy theory to failure of material in an impact event would be to measure failure in terms of energy density rather than ultimate strain. This may be possible with the ABAQUS/Explicit program by utilizing the VUMAT user subroutine. In that subroutine, the energy dissipated by plasticity per unit volume (i.e., PENER) would be identified as a state variable. This variable would then be used in the subroutine to control element deletion in the mesh. An element would be deleted when its energy density ex- 
ceeds the area under the true stress-true strain curve obtained from uniaxial tests. The fact that the stress in an element has not dropped to zero when deleted from the model, though, could cause convergence problems in the solution. The subroutine would be used only to determine material failure; i.e. it would not be used to alter the constitutive model. This process of using VUMAT to implement a failure criterion based on energy density has not been demonstrated in this study. Therefore, it is not known how much this would affect the outcome of a drop event analysis versus using ultimate strain as the basis for failure.

\section{CONCLUSION}

A failure criterion has been established and presented herein to allow for more realistic simulations of accidental drops of fuel containers than did previous criteria. The basic approach is to more fully recognize the strength and ductility of the material in an impact event. The new criterion was developed such that analyses using the criterion are expected to predict failure in material earlier than it would actually occur during an impact. The guidelines and recommendations presented (based on the new failure criterion) should be generally applicable for modeling ductile materials in impact events. They may not, however, represent the best approach in all situations. The analyst must consider any phenomena that may impair ductile material behavior in a particular situation, and model the behavior accordingly. 


\section{REFERENCES}

1. C. A. Moore letter to R. G. Rahl, 1995, "Austenitic Stainless Steel Material Properties for Use in Drop Calculations," Lockheed Idaho Technologies Company, CAM-02-95, May 10.

2. J. A. Collins, 1993, Failure of Materials in Mechanical Design, John Wiley \& Sons, Inc., Second Edition.

3. A. Mendelson, 1983, Plasticity: Theory and Application, Krieger Publishing Co., Reprint Edition.

4. R. L. Brockenbrough, 1994, Structural Alloys Handbook, A 36 Steel, Purdue Research Foundation, West Lafayette, Indiana.

5. Structural Alloys Handbook, 1995, Metals and Ceramics Information Center, CINDAS/ Purdue University.

6. W. D. Richins and G. K. Miller, 1995, "Analysis of the ATR Fuel Element Swaging Process," INEL-95/0558, December.

7. L. B. Shappert, 1970, Cask Designers Guide, Oak Ridge National Laboratory, ORNLNSIC-68, February.

8. H. E. Boyer, 1987, Atlas of Stress-Strain Curves, ASM International.

9. N. E. Dowling, 1993, Mechanical Behavior of Materials, Prentice Hall.

10. P. W. Bridgman, 1964, Studies in Large Plastic Flow and Fracture, Harvard University Press. 